\title{
recildunds
}

Revista Cientifica Mundo de la Investigación y el Conocimiento

Freddy Leónidas Monge Paladines ${ }^{\text {aa }}$ Victoria Magdalena Paladines Ríos ${ }^{\text {b }}$

Daño cardíaco por fiebre reumática activa

Heart damage from active rheumatic fever

Revista Científica Mundo de la Investigación y el Conocimiento. Vol. 3 núm. 4., diciembre, ISSN: 2588-073X, 2019, pp. 256-278

DOI: $10.26820 /$ recimundo/3.(4).diciembre.2019.256-276

URL: http://recimundo.com/index.php/es/article/view/662

Código UNESCO: 3205 Medicina Interna

Tipo de Investigación: Artículo de Revisión

(C) RECIMUNDO; Editorial Saberes del Conocimiento, 2019

Recibido: 15/09/2019

Aceptado: 23/11/2019

Publicado: 30/12/2019

Correspondencia: fmongepaladines_91@yahoo.com

a. Médico; Investigador Independiente; Guayaquil, Ecuador; fmongepaladines_91@yahoo.com

b. Médico; Investigador Independiente; Guayaquil, Ecuador; vicpal_2705@yahoo.com 


\section{Daño cardíaco por fiebre reumática activa}

Vol. 3, núm. 4., (2019)

Freddy Leónidas Monge Paladines; Victoria Magdalena Paladines Ríos

\section{RESUMEN}

Para la construcción bibliográfica del artículo, se consideró como evento esencial su ubicación en el campo científico documental, fue necesario establecer su propósito orientado a analizar el daño cardíaco por fiebre reumática activa, caracterizado por la revisión de fuentes secundarias encontradas durante la lectura de artículos, revistas digitales entre otros. Para llegar a entender que, la presencia del daño cardíaco responde a diferentes factores entre los cuales la fiebre reumática activa es uno de ellos, pues, al presentarse una infección en las vías respiratorias altas, trae como resultado subsiguiente la fiebre enfermedad inflamatoria, con complicaciones no supurativa y tardía de infecciones por el Estreptococo B, hemolítico del grupo A, básicamente faringe amigdalitis y escarlatina; afecta fundamentalmente: corazón, articulaciones, sistema nervioso central, piel y tejido subcutáneo. Puede causar daño cardíaco permanente, incluidos en las válvulas cardíacas e insuficiencia cardíaca. Los tratamientos pueden reducir el daño causado por la inflamación, aliviar el dolor, otros síntomas y prevenir la reaparición de la fiebre reumática. Sin embargo, la relación entre las infecciones estreptocócicas y la fiebre reumática no está clara, pero parece ser que la bacteria engaña al sistema inmunitario. Los estreptococos contienen una proteína similar a la que poseen ciertos tejidos del cuerpo. Entonces, las células del sistema inmunitario que normalmente atacan la bacteria pueden tratar a los propios tejidos del cuerpo como si fueran agentes infecciosos, especialmente los tejidos del corazón, articulaciones, piel y sistema nervioso central. Esta reacción del sistema inmunitario termina en una inflamación que produce un daño permanente al corazón que, ocurre a los 10 o 20 años después de la enfermedad original. Los problemas más frecuentes afectan la válvula situada entre las dos cavidades izquierdas del corazón (válvula mitral), pero las otras válvulas pueden verse afectadas, originando estenosis de la válvula, insuficiencia valvular y daño del músculo cardíaco.

Palabras Claves: Corazón; Daño Cardíaco; Fiebre Reumática; Activa. 


\title{
Daño cardíaco por fiebre reumática activa
}

Vol. 3, núm. 4., (2019)

Freddy Leónidas Monge Paladines; Victoria Magdalena Paladines Ríos

\begin{abstract}
For the bibliographic construction of the article, its location in the documentary scientific field was considered as an essential event, it was necessary to establish its purpose aimed at analyzing heart damage by active rheumatic fever, characterized by the review secondary sources found while reading articles, digital magazines, among others. To come to understand that, the presence of heart damage responds to different factors among which active rheumatic fever is one of them, because, when an upper respiratory infection occurs, it results in subsequent fever inflammatory disease, with non-supheative and late complications of Streptococcus B infections, group A hemolytic disease, basically pharynx tonsillitis and scarlet fever; fundamentally affects: heart, joints, central nervous system, skin and subcutaneous tissue. May cause permanent heart damage, including heart valves and car insufficiency. Then, immune system cells that normally attack the bacteria can treat the body's own tissues as if they were infectious agents, especially the tissues of the heart, joints, skin, and central nervous system. This immune system reaction ends in inflammation that causes permanent damage to the heart that occurs 10 to 20 years after the original disease. The most common problems affect the valve between the two left chambers of the heart (mitral valve), but the other valves may be affected, causing valve stenosis, valve regurgitation, and heart muscle damage.
\end{abstract}

Keywords: Heart; Heart Damage; Rheumatic Fever; Active. 


\section{Daño cardíaco por fiebre reumática activa}

Vol. 3, núm. 4., (2019)

Freddy Leónidas Monge Paladines; Victoria Magdalena Paladines Ríos

\section{Introducción.}

Los aspectos relativos a la presencia de un daño cardíaco llevan a buscar informaciones precisas y coherentes, vinculadas con el funcionamiento del corazón, el cual es una bolsa compuesta por músculos con vasos sanguíneos que entran y salen de él, situado entre los pulmones, a la izquierda del tórax, apoyado sobre el diafragma y detrás del esternón. La masa muscular que lo constituye recibe el nombre de miocardio formada por tejido muscular de tipo cardíaco, que se caracteriza por no estar sometido a la voluntad, sino que funciona de manera automática (a diferencia de los músculos del brazo, por ejemplo).

Al precisar su estructura, se visualiza en su interior cuatro cámaras (dos aurículas y dos ventrículos) separadas por unas válvulas llamadas tricúspide (a la derecha) y mitral (a la izquierda). Unas gruesas paredes musculares separan la parte derecha e izquierda del corazón, que actúan como dos corazones coordinados: la parte izquierda para la sangre arterial (rica en

oxígeno), y la derecha para la venosa (pobre en oxígeno). La función del corazón es bombear la sangre a todos los rincones del organismo, que recoge oxígeno a su paso por los pulmones y circula hasta el corazón para ser impulsada a todas las partes del cuerpo. Después de su viaje por el organismo, la sangre queda sin oxígeno y es enviada de nuevo al corazón para que éste la bombee a los pulmones con el fin de recoger más oxígeno. Así se completa el ciclo.

Para impulsar la sangre por los vasos de todo el cuerpo, el corazón se contrae y se relaja rítmicamente. La fase de contracción se llama sístole, que corresponde a la expulsión de la sangre fuera de la cavidad. A esta fase sistólica le sigue una fase de relajación muscular llamada diástole, en la que se pueden distinguir dos etapas: una de relajación y otra de succión para 


\section{Daño cardíaco por fiebre reumática activa}

Vol. 3, núm. 4., (2019)

Freddy Leónidas Monge Paladines; Victoria Magdalena Paladines Ríos

arrastrar la sangre hasta el interior. El ritmo cardíaco, intensidad y fuerza de contracción y relajación están regulados por los centros situados en el hipotálamo (en el cerebro), que elaboran los impulsos nerviosos adecuados, por sustancias químicas como la adrenalina y noradrenalina, que son hormonas que actúan sobre el corazón.

Como el corazón también necesita oxígeno para funcionar, en el exterior hay unos vasos sanguíneos que se lo proporcionan. Si alguno de estos vasos queda obstruido, impidiendo la llegada de suficiente sangre, los músculos del corazón se van degenerando y se produce entonces una angina de pecho o infarto de miocardio. Pero no sólo, estas circunstancias pueden generar daño cardíaco, existen otros factores importantes entre los cuales se cita la fiebre reumática.

En este sentido, Rodríguez y Panadero (2017), define a la fiebre reumática "como un proceso inflamatorio generalizado en el que se encuentran implicados muchos órganos: el corazón, principalmente, articulaciones y sistema nervioso central”. (p. 58). Es decir, su aparición responde a la presencia de una infección que se produce por la presencia de Streptococcus pyogenes (Estreptococo Beta-hemolítico del grupo A o $\boldsymbol{S G A}$, de la clasificación de Lancefield), en la garganta después de un periodo de latencia de aproximadamente tres semanas. Es la causa más habitual de enfermedad cardiaca adquirida en niños y adultos jóvenes en todo el mundo; es posible que las personas que han sufrido un episodio de fiebre reumática poseen una tendencia a desarrollar brotes con infecciones por estreptococos repetidas.

Dentro de este orden de ideas, se puede indicar que es probable que la fiebre reumática sea el resultado de una reacción hiperinmune a alergia bacteriana o a autoinmunidad. En los últimos cincuenta años, la fiebre reumática cada vez se ha hecho progresivamente menos 


\section{Daño cardíaco por fiebre reumática activa}

Vol. 3, núm. 4., (2019)

Freddy Leónidas Monge Paladines; Victoria Magdalena Paladines Ríos

frecuente y su presentación es ahora excepcional en muchos países, sobre todo en el primer mundo. De todas formas, en aquellos en vías de desarrollo (Asia, África y Sudamérica), es una de las causas más frecuentes de muerte de origen cardiaco. La disminución de la fiebre reumática en los países occidentales no sólo se debe al uso de los antibióticos, sino que también es atribuible al cambio en la virulencia del estreptococo y a cambios en los hábitos sociales. La evidencia microscópica de fiebre reumática aguda se caracteriza porque afecta particularmente a tejidos envueltos por endotelio, como son los vasos sanguíneos, endocardio, pericardio y membranas sinoviales.

Cabe agregar que, Las lesiones de la fiebre reumática son más obvias en relación con las válvulas cardiacas y el pericardio. Los anillos valvulares se engruesan debido al edema y la infiltración por capilares. Aparecen formaciones verrucosas de coloración amarillenta o grisácea a lo largo de las líneas de cierre de las válvulas. Es típica la afectación de los anillos valvulares de las válvulas mitral y aórtica, y rara vez asientan en las válvulas pulmonar o tricúspide. La fiebre reumática crónica es una secuela de la fiebre reumática aguda, y muchos de sus síntomas son debidos a la fibrosis que resulta durante la curación o cicatrización de las lesiones de la fiebre reumática aguda. Los factores que contribuyen a la patogenia de la fiebre reumática están relacionados tanto con el agente causal como con el huésped.

Sin embargo a nivel mundial, se han realizado diferentes estudios relacionados con las infecciones estreptocócicas y su secuela no supurativa; por ello, se han establecido laboratorios especializados en microbiología de los estreptococos, organizaciones que aportan informaciones relevantes en cuanto a los diferentes grupos serológicos de estreptococos betahemolíticos en relación a su distribución, asimismo, destacan la presencia de los diferentes tipos de 


\section{Daño cardíaco por fiebre reumática activa}

Vol. 3, núm. 4., (2019)

Freddy Leónidas Monge Paladines; Victoria Magdalena Paladines Ríos

estreptococos tipo A, eventos de significación para el área científica en materia de salud, así como, ayudar a generar nuevos conocimientos en diferentes enfermedades y en especial sobre la fiebre reumática.

Según los avances alcanzados hoy en día en cuanto a la identificación de los síntomas y signos de la fiebre reumática, permiten resaltar que tiene pocos síntomas o varios, los cuales, cambian en el transcurso de la enfermedad. La aparición de la fiebre reumática generalmente ocurre después de dos a cuatro semanas posteriores a una infección de garganta por estreptococos.

Los signos y síntomas de la fiebre reumática, que son el resultado de la inflamación del corazón, articulaciones, piel o el sistema nervioso central, pueden incluir: fiebre, dolor de las articulaciones con el movimiento, palpación, con mayor frecuencia en las rodillas, tobillos, codos, muñecas, articulaciones enrojecidas, calientes al tacto o hinchadas, bultos (nódulos) pequeños e indoloros debajo de la piel, dolor de pecho, soplo cardíaco, fatiga, erupción cutánea de aspecto plano o levemente elevado, indolora, con bordes irregulares (eritema marginado), movimientos corporales espasmódicos e incontrolables (conocida como baile de San Vito), con mayor frecuencia en las manos, pies, rostro y arrebatos de comportamiento inusual, como llorar o reírse de manera inoportuna. La única manera de prevenir la fiebre reumática es tratar la faringitis estreptocócica o la escarlatina de inmediato con un ciclo completo de los antibióticos adecuados.

En función de los planteamientos anteriores, se puede decir que los mismos son un aporte de relevancia para el desarrollo del presente artículo, que busca proporcionar un análisis relativo 


\section{Daño cardíaco por fiebre reumática activa}

Vol. 3, núm. 4., (2019)

Freddy Leónidas Monge Paladines; Victoria Magdalena Paladines Ríos

al daño cardíaco por fiebre reumática, lo que hace mirar el comportamiento del cuerpo humano ante la presencia de infecciones originadas por estreptococos tipo A y en consecuencia, sus síntomas y signos conducen a generar inflaciones de las articulaciones y el corazón siendo el órgano que es más afectado debido a la presencia de estos microorganismos en las vías respiratorias altas y afectan al miocardio y pericardio.

\section{Método.}

En el marco conceptual de lo científico, es determinante la selección de un camino metodológico caracterizado por la presencia de argumentos reales que permitan la organización de los contenidos previamente establecidos. En esta dirección, Ramos (2019), define al método "como una herramienta competente que ofrece lineamientos estrictamente vinculados con la naturaleza investigativa para lograr respuestas a los objetivos trazados". (p.36). Por lo tanto, es importante ubicar el método inductivo como preferencia para la realización del artículo, mediante su intervención se propusieron diferentes situaciones de manera individual, para luego complementarlas y convertirlas en consideraciones generales.

\section{Tipo de Investigación}

La selección del tema a abordar se convierte en el eje central para fijar una posición científica en cuanto al tipo de investigación, la misma responde a lo documental, vista por Duarte (2018) “como un trabajo caracterizado por la revisión de diferentes materiales impresos, digitales u otro tipo, que facilitan la construcción de ideas ampliamente argumentadas por el investigador". (p. 21). Es decir, las condiciones temáticas son factores esenciales para indicar que el contenido a desarrollar se encuentra insertado en el campo de las investigaciones 


\section{Daño cardíaco por fiebre reumática activa}

Vol. 3, núm. 4., (2019)

Freddy Leónidas Monge Paladines; Victoria Magdalena Paladines Ríos

documentales, para lo cual, se hizo necesario incorporar diferentes técnicas de apoyo capaces de llevar a los planteamientos requeridos de manera coherente y vinculados con los constructos preestablecidos.

\section{Fuentes Documentales}

La incorporación del método inductivo, se convierte en el eje básico para relacionar las técnicas requeridas antes y durante la realización del contenido temático; por ello, se consideraron aquellas acciones vinculadas con la lectura como principal herramienta que hace posible combinar ideas, reportar hallazgos de manera adecuada a las necesidades de investigación, por ello, para darle flexibilidad a los aspectos que forman parte de los argumentos, se incluye la revisión bibliográfica, mediante un arqueo de fuentes esenciales que dan la respectiva consistencia teórica al tema a tratar. Según Ramos (ob.cit) la presencia de las fuentes documentales en los estudios científicos "son vitales para organizar los aspectos estructurales del trabajo científico". (p. 41).

\section{Técnica de Recolección de Información}

Con el fin de darle continuidad al proceso investigativo, se acompañaron las fuentes documentales con las diferentes técnicas esenciales mediante las cuales, se pudo plantear de forma dinámica los eventos básicos del proceso científico. Apoyado este planteamiento en Duarte (ob.cit) "la dinámica del hecho investigativo debe responder a la existencia de técnicas capaces de orientar su elaboración de acuerdo con la naturaleza seleccionad". (p.26). Ante lo citado, es importante destacar que, para la construcción del trabajo se consideraron como técnicas, la lectura interpretativa, revisión bibliográfica, análisis de contenidos fijados desde la 


\section{Daño cardíaco por fiebre reumática activa}

Vol. 3, núm. 4., (2019)

Freddy Leónidas Monge Paladines; Victoria Magdalena Paladines Ríos

perspectiva de encontrar referencias ajustadas a los tópicos que conforman el trabajo científico y así, llegar finalmente a plantear las respectivas conclusiones que dan una visión global del tema abordado.

\section{Resultados.}

La naturaleza metodológica que caracteriza a este artículo, lleva a estimar como elementos teóricos, aquellos aspectos encargados de conformar cada constructo; es decir, se procede a la organización de los eventos que forman parte del trabajo científico a fin de ofrecer de forma dinámica nuevas informaciones para su valoración en el campo de la medicina.

\section{El Corazón como Sistema Circulatorio}

El sistema circulatorio forma una unidad funcional que se extiende a todo el cuerpo y tiene como órgano central el corazón, que mantiene la sangre en movimiento para que exista la vida celular. Las enfermedades del corazón repercuten en todo el organismo. Cualquiera de las partes que lo componen puede enfermar y ocasionar cuadros clínicos diversos que, a la larga, evolucionan hacia una situación común de insuficiencia cardiaca. Según la estructura cardiaca a la que afecta pueden producirse los siguientes trastornos cardiovasculares, que son descritos por Villa y Mandell (2016), las enfermedades valvulares se encuentran: Miocardiopatías: Afección del músculo que forma la pared del corazón (miocardio). Cardiopatía isquémica: Afecta a los vasos que irrigan el músculo cardiaco (arterias coronarias). Entre los síntomas habituales de las enfermedades del corazón, de acuerdo con los autores citados, se precisan los siguientes: 


\section{Daño cardíaco por fiebre reumática activa}

Vol. 3, núm. 4., (2019)

Freddy Leónidas Monge Paladines; Victoria Magdalena Paladines Ríos

DisnNeiea: Dificultad para respirar habitualmente desencadenada por el esfuerzo pero que en casos severos se da también en reposo.

Angina de pecho: Dolor fuerte y opresivo en la parte anterior al pecho. Se produce por falta de riego del corazón (isquemia). Es la expresión crónica de la enfermedad coronaria. Se manifiesta por dolor en el pecho al realizar un esfuerzo o ejercicio físico. El tratamiento de esta enfermedad pasa por la adopción de medidas preventivas que eliminen los factores de riesgo (tabaco, colesterol, hipertensión arterial, diabetes); la ingesta de fármacos como el ácido acetilsalicílico y los betabloqueantes, y la revascularización mediante cateterismo o cirugía.

Palpitación: sensación anormal del latido del corazón que se percibe en el pecho.

La enfermedad más común es la cardiopatía isquémica, que constituye la principal causa de mortalidad en los países desarrollados. Esta patología es producida por la arteriosclerosis de las arterias coronarias que afectan a la irrigación del corazón. La cardiopatía isquémica da lugar al infarto de miocardio que es la necrosis (muerte) de un segmento del corazón por falta de riesgo debido a la obstrucción de la arteria coronaria. Esta obstrucción se debe a la formación de un trombo en la placa de arteriosclerosis en el interior de la arteria. Este cuadro clínico provoca hasta un $30 \%$ de mortalidad.

En la actualidad existen técnicas de tratamiento que consisten en desatascar las arterias de manera precoz. Estos procedimientos tienen mucho éxito si se realizan en las primeras dos horas (mortalidad del $2 \%$ si se realizan en la primera hora). Por ello es importante que el paciente llegue cuanto antes al hospital. 


\section{Daño cardíaco por fiebre reumática activa}

Vol. 3, núm. 4., (2019)

Freddy Leónidas Monge Paladines; Victoria Magdalena Paladines Ríos

Las miocardiopatías, por su parte, afectan al músculo del corazón, que pierde capacidad de contracción; mientras que las valvulopatías se deben al mal funcionamiento de las válvulas del corazón que no cierran adecuadamente o no abren lo suficiente. Estas dos enfermedades dan lugar a la insuficiencia cardiaca porque dificultan la función de bombeo del corazón. No obstante, estos trastornos son mucho menos frecuentes que la cardiopatía isquémica. Precisan tratamiento farmacológico, y en el caso de las enfermedades valvulares, puede ser necesario el recambio de las válvulas por prótesis. En los casos extremos de miocardiopatía puede valorarse la necesidad de un trasplante cardiaco.

También se precisa como enfermedad del corazón la cardiopatía reumática las cuales agregan a la actividad del respectivo órgano un daño al mismo, además, representa el interés para el investigador, razón por la cual, se precisan a continuación una serie de aportes que serán los encargados de ampliar cada uno de los elementos que fueron entendidos como significantes para su respectivo abordaje.

\section{Daño Cardíaco por Fiebre Reumática}

La enfermedad cardiovascular es un problema frecuente e insuficientemente reconocido en pacientes con trastornos reumáticos sistémicos. Los pacientes pueden presentar una enfermedad asociada a afección cardiaca en el momento del diagnóstico o en una fase posterior del curso de la enfermedad. Las manifestaciones varían según el tipo y todas las estructuras del corazón pueden verse afectadas o pueden causar morbilidad y mortalidad importantes. Las manifestaciones de la enfermedad cardiaca en estos pacientes van de subclínicas a graves y pueden requerir un tratamiento inmunosupresor agresivo. 


\section{Daño cardíaco por fiebre reumática activa}

Vol. 3, núm. 4., (2019)

Freddy Leónidas Monge Paladines; Victoria Magdalena Paladines Ríos

La detección temprana es importante para instaurar con rapidez un tratamiento apropiado. El tratamiento de la afección cardiaca asociada a la enfermedad se basa en la gravedad; las manifestaciones más graves requieren a menudo un tratamiento combinado con corticoides y fármacos citotóxicos. Se ha identificado de manera creciente aterosclerosis prematura en los pacientes con lupus eritematoso sistémico y artritis reumatoide, lo que puede conducir a una muerte coronaria prematura respecto a la población general. Un control agresivo de la inflamación sistémica en estas enfermedades puede conducir a reducir el riesgo de cardiopatía isquémica. Aunque el tratamiento agresivo de la enfermedad reumática primaria se ha asociado a una reducción de las tasas de mortalidad, no se han formulado directrices específicas para la prevención de la cardiopatía isquémica en este grupo de pacientes y las recomendaciones actuales incluyen el control agresivo y el seguimiento de los factores de riesgo tradicionales.

En relación a lo anterior, Torres (2017), precisa que las enfermedades reumáticas sistémicas son trastornos inflamatorios autoinmunitarios que afectan a múltiples órganos y con frecuencia producen alteraciones en los vasos sanguíneos y el corazón. La cardiopatía puede producirse en pacientes con un diagnóstico establecido de un trastorno reumático o ser la forma de presentación inicial en los pacientes sin un diagnóstico previo.

Es posible que el cardiólogo sea el primer especialista que evalúe al paciente con una enfermedad reumática subyacente que acude con síntomas iniciales relacionados con el corazón. La afección cardiaca en las enfermedades reumáticas puede variar entre asintomática o leve y grave o peligrosa para la vida, y constituye una causa importante de morbimortalidad. Los pacientes pueden no presentar síntomas cardiacos clínicos manifiestos, lo que hace que el diagnóstico de la cardiopatía resulte más difícil. 


\section{Daño cardíaco por fiebre reumática activa}

Vol. 3, núm. 4., (2019)

Freddy Leónidas Monge Paladines; Victoria Magdalena Paladines Ríos

Además de causar anomalías miocárdicas, valvulares, pericárdicas y del sistema de conducción, los trastornos reumáticos se han asociado a aterosclerosis prematura, que da lugar a cardiopatía isquémica a una edad temprana. El aumento del riesgo de eventos coronarios no puede atribuirse únicamente a los factores de riesgo cardiovascular (CV) tradicionales, ya que puede ser el resultado de una inflamación sistémica crónica causada por la enfermedad reumática. La prevalencia y relevancia de la cardiopatía isquémica han aumentado aún más como consecuencia de los avances en el tratamiento, que han aumentado la esperanza de vida de los pacientes con enfermedades reumáticas. Se analizan aquí las manifestaciones cardiacas de las enfermedades reumáticas específicas que se asocian con mayor frecuencia a cardiopatías.

Es decir, la fiebre reumática puede dañar los tejidos del organismo causando hinchazón, pero el mayor peligro de la enfermedad es el daño que puede ocasionar al corazón. Más de la mitad de las veces, la fiebre reumática produce una cicatrización de las válvulas del corazón. Esta cicatrización puede estrechar la válvula y hacer que sea más difícil que ésta se abra bien o se cierre por completo. A su vez, el corazón tiene que esforzarse más por bombear sangre al resto del organismo. Este daño valvular puede dar lugar a una enfermedad denominada «cardiopatía reumática» la cual, con el tiempo, puede ocasionar una insuficiencia cardíaca congestiva.

Según Torres (ob.cit) menos de un 0,3 por ciento de los que padecen amigdalitis estreptocócica contraen también fiebre reumática. La fiebre reumática es más común entre los niños de 5 a 15 años de edad, pero los adultos también pueden padecer esta enfermedad. Los médicos creen que un sistema inmunitario debilitado puede aumentar las probabilidades de padecer fiebre reumática. Y aunque los antibióticos han reducido el número de casos de fiebre reumática en los países desarrollados, aún se registran miles de casos. 


\section{Daño cardíaco por fiebre reumática activa}

Vol. 3, núm. 4., (2019)

Freddy Leónidas Monge Paladines; Victoria Magdalena Paladines Ríos

Asimismo, complementa que la fiebre reumática aparece entre el 0,5 y el 5\% de los pacientes que hacen una faringoamigdalitis estreptocócica. La incidencia es más baja en los casos aislados $(0,3-0,5 \%)$ y más alta en los casos epidémicos $(3-5 \%)$. También la probabilidad es más alta en quienes han tenido un episodio de la fiebre reumática, disminuyendo a medida que pasan los años desde el episodio previo. Hay evidencias de la existencia de cepas de estreptococos Grupo A que producen un mayor porcentaje de fiebre reumática.

De este modo, se puede indicar que el daño cardíaco por fiebre reumática, afecta el pericardio, miocardio y endocardio con algunas lesiones características: miocardio: produce un degeneración fibrinoidea del colágeno, siendo su lesión característica el granuloma de Aschoff; Lesión endocárdica: el daño principal es a nivel de las válvulas, donde se produce una valvulitis verrucosa, que a largo plazo determina lesiones fibrosas, con adherencia, engrosamiento y retracción de velos y cuerdas tendíneas. Lesión pericárdica: derrame serofibrinoso de tipo inespecífico.

En general se presenta como un cuadro febril, de evolución más o menos insidiosa, con aparición de las siguientes manifestaciones clínicas características, sin embargo un porcentaje indeterminado de episodios pasa desapercibido.

Artritis: (Incidencia aprox 70-80\%): típicamente es una poliartritis migratoria de grandes articulaciones, que en la práctica no deja secuelas.

Carditis: (Incidencia total aprox 40 - 60\%; aislada aprox. 15 - $20 \%$ ) Generalmente la carditis aparece dentro de las primeras semanas del episodio (70\% en la primera semana), de manera que si no hay carditis en los primeros meses el pronóstico es muy bueno. Puede 


\section{Daño cardíaco por fiebre reumática activa}

Vol. 3, núm. 4., (2019)

Freddy Leónidas Monge Paladines; Victoria Magdalena Paladines Ríos

manifestarse por: Soplos de Insuficiencia Mitral o Aórtica; Frotes pericárdicos; Cardiomegalia, galope, congestión pulmonar. En la mayoría de los casos, las carditis son poco sintomáticas, pero pueden llegar a ser muy graves, con insuficiencia cardíaca congestiva y muerte del paciente. En pacientes en que la fiebre reumática se presenta como carditis aislada, sin artritis ni corea, el diagnostico puede ser difícil.

Corea: (Incidencia aprox 10-20\%) Es un trastorno del sistema nervioso central caracterizado por movimientos descoordinados, inesperados $\mathrm{e}$ involuntarios. Es una manifestación clínica retardada de fiebre reumática y habitualmente aparece varias semanas después de la artritis. Ocasionalmente se presenta en forma aislada.

Eritema marginado y nódulos subcutáneos (Incidencia aprox 2-3\% c/u.). Fenómeno inhabitual en algunos países.

Otros síntomas: Compromiso del estado general, fiebre, artralgias, etc. como manifestación de un proceso inflamatorio general.

Los episodios de fiebre reumática. tienden a remitir espontáneamente: un $75 \%$ antes de 6 semanas y un $90 \%$ antes de 12 semanas. Sin embargo, un 5\% se prolonga más de 6 meses. En Chile la mortalidad es baja $(<1 \%)$ y se debe a casos de carditis grave. Pueden aparecer nuevos episodios de fiebre reumática. sólo si hay nuevos episodios de infección faringoamigdaliana por estreptococo Grupo A: de ahí la importancia de la prevención. A más largo plazo, la presencia de daño cardíaco permanente dependerá de la duración y gravedad de la carditis; de la aparición de nuevos brotes de fiebre reumática de acuerdo con la magnitud y localización del daño valvular. 


\section{Daño cardíaco por fiebre reumática activa}

Vol. 3, núm. 4., (2019)

Freddy Leónidas Monge Paladines; Victoria Magdalena Paladines Ríos

Por ello, para lograr eficiencia en el diagnóstico de la fiebre reumática, es relevante considerar ciertos criterios destacados por Neira (2018), quien indica que no existen pruebas clínicas, de laboratorio y otras que establezcan el diagnóstico definitivo de fiebre reumática. En la mayoría de los casos, dos o tres semanas después de producirse la faringitis aguda, el niño empieza a encontrarse mal, pierde el apetito y se queja de dolores en las articulaciones. La fiebre está presente pero normalmente no es muy alta.

Existen unos criterios diagnósticos, que establecen una serie de signos a través de los cuales se puede realizar el diagnóstico de fiebre reumática. Existen criterios mayores: carditis, poliartritis, nódulos subcutáneos, eritema marginado y corea, y criterios diagnósticos menores. La presencia de dos criterios mayores o un criterio mayor y dos menores, indica que existe una alta probabilidad de padecer fiebre reumática aguda. Los cuales se presentan en el siguiente cuadro.

Cuadro $\mathbf{N}^{\circ}$ 1. Criterio de Diagnóstico de Fiebre Reumática

\begin{tabular}{|l|l|}
\hline MAYORES & MENORES \\
\hline CARDITIS & HALLAZGOS CLÍNICOS \\
& Fiebre \\
& Artralgia \\
\hline POLLARTRITIS & HALLAZGOS DE \\
& LABORATORIO \\
& Aumento de reactantes de base \\
& aguda (VSG y PCR) \\
\hline COREA & \\
\hline ERITEMA MARGINADO & \\
\hline NODULOS SUBCUTANEOS & \\
\hline
\end{tabular}

Fuente: Elaboración Propia 


\section{Daño cardíaco por fiebre reumática activa}

Vol. 3, núm. 4., (2019)

Freddy Leónidas Monge Paladines; Victoria Magdalena Paladines Ríos

En la mayoría de los casos existe una moderada leucocitosis (12000-15000). Se puede objetivar un aumento de la velocidad de sedimentación globular (VSG) y de la proteína C reactiva (PCR), que son indicadores no específicos de inflamación tisular. Estos dos parámetros están casi siempre elevados durante los episodios agudos de la enfermedad, en pacientes con carditis o polartritis, pero son normales en pacientes con corea. La VSG es una buena indicadora del curso de la enfermedad. Cuando la actividad reumática cesa, se observa una disminución de la VSG. También puede estar elevada en pacientes con anemia y puede ser normal o estar disminuida en pacientes con insuficiencia cardiaca congestiva. En cambio, la PCR no se afecta por el grado de anemia o de insuficiencia cardiaca.

En el momento del diagnóstico de fiebre reumática aguda, sólo un once por ciento de los pacientes tiene un cultivo positivo para SGA. Existen muchas pruebas diagnósticas de detección rápida de antígenos de SGA. La mayoría tiene un alto grado de especificidad, pero baja sensibilidad. Una prueba negativa no excluye la presencia de SGA en la faringe, mientras que una prueba positiva no distingue entre una infección reciente que pueda ser asociada a fiebre reumática o a un portador crónico faríngeo. Debido a que la presencia de SGA en la faringe no es indicativo de infección activa, una elevación de títulos de anticuerpos antiSGA, dan mayor fiabilidad para poder confirmar una infección por SGA reciente. 


\section{Daño cardíaco por fiebre reumática activa}

Vol. 3, núm. 4., (2019)

Freddy Leónidas Monge Paladines; Victoria Magdalena Paladines Ríos

\section{Imagen $\mathbf{N}^{\circ}$ 1. Fiebre Reumática}

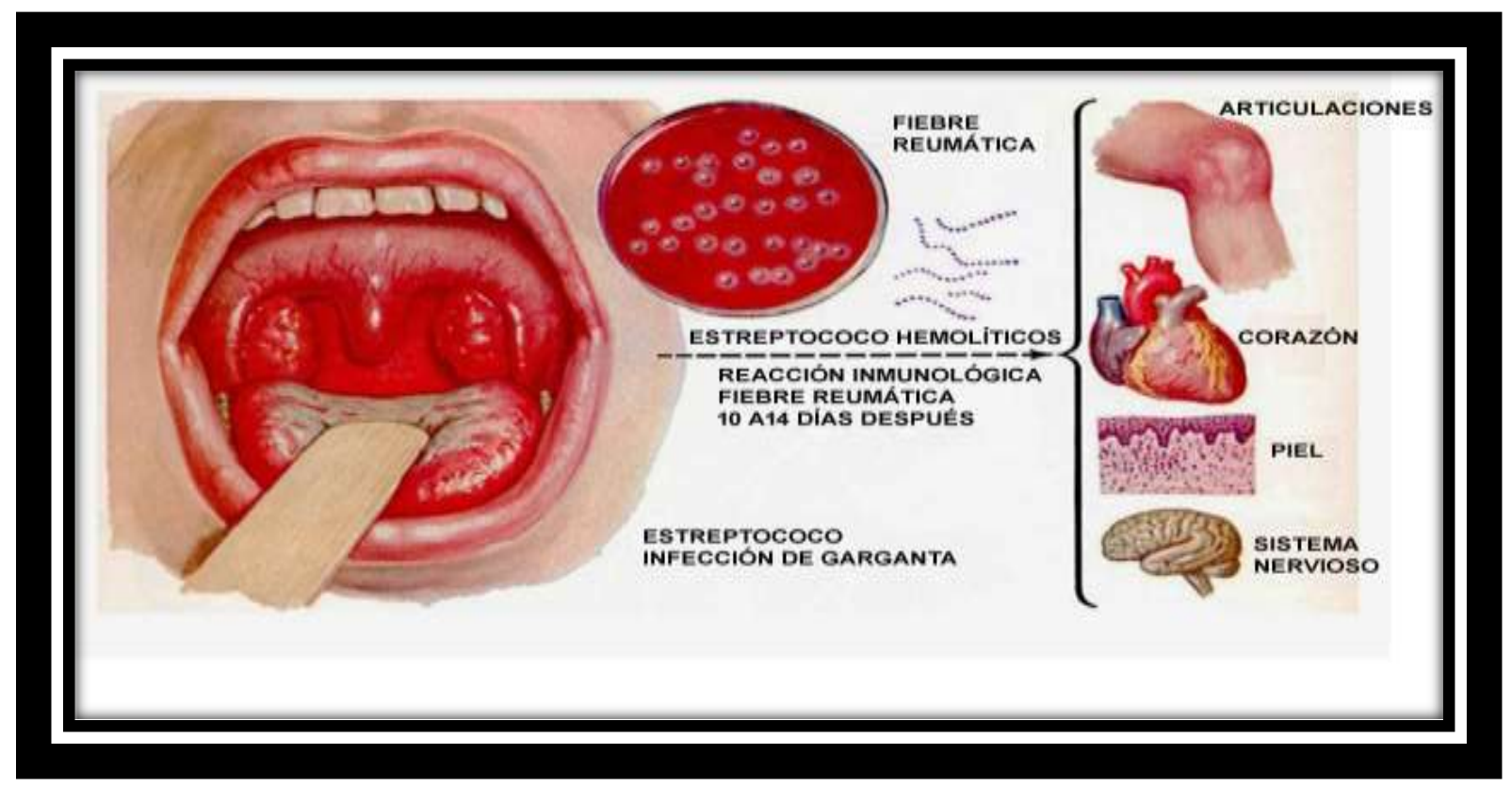

Fuente: Neira (ob.cit)

El diagnóstico de fiebre reumática normalmente es difícil, porque el cuadro completo de síntomas está raramente presente. Aunque los criterios diagnósticos son de mucho valor, dependen también de una buena exploración y de una correcta elaboración a tiempo de las pruebas diagnósticas. Normalmente una infección de garganta es infravalorada porque ésta está producida por microorganismos distintos de los estreptococos. Además, cuando se ve una poliartritis, puede ser erróneamente diagnosticada cuando sólo se presenta con dolores articulares difusos. También los soplos cardiacos al ser frecuentes en procesos como fiebre de cualquier causa, pueden ser desechados. Las enfermedades que son especialmente importantes en el diagnóstico diferencial de fiebre reumática aguda son: artritis bacteriana, artritis reumatoide y endocarditis infecciosa subaguda. En la mayoría de los casos de artritis séptica aguda, el proceso 


\section{Daño cardíaco por fiebre reumática activa}

Vol. 3, núm. 4., (2019)

Freddy Leónidas Monge Paladines; Victoria Magdalena Paladines Ríos

se limita a una sola articulación, y la inflamación se extiende a los tejidos adyacentes. El diagnóstico puede ser confirmado con el examen del líquido articular.

La fiebre reumática es una secuela tardía de una faringitis GAS no tratada. Suele producirse inicialmente entre los 5-15 años de edad, y afecta a corazón, articulaciones mayores y piel. El criterio diagnóstico principal incluye poliartritis migratoria (46-66\% de los casos), en general de rodillas, tobillos, codos y muñecas; carditis (53-68\% clínica y subclínica adicional diagnosticada por ecocardiograma), en la que se produce típicamente inflamación de la válvula mitral $(90 \%)$ o la aorta (10\%) en forma aislada, pero se ha informado de cualquier combinación de afectación de las 4 válvulas; corea de Sydenham (8-15\%); eritema marginado (1-11\%); y nódulos subcutáneos de las superficies flexoras (1-8\%). Entre los criterios menores se incluyen: fiebre (35-75\% de los casos), artralgia (35-56\%), bloqueo cardiaco de primer grado (prolongación del intervalo PR) (20-29\%) y marcadores inflamatorios elevados (53-91\%). No siempre hay una infección GAS previa clínicamente aparente.

Al hacer referencia al tratamiento de la fiebre reumática incluye: 1) tratamiento de la faringitis para erradicar GAS, con penicilina como terapia de primera línea, 2) tratamiento antiinflamatorio, normalmente aspirina en la fase aguda, aunque a veces se sugiere el uso de corticosteroides, especialmente con carditis grave, y 3) profilaxis antibiótica secundaria para prevenir la recurrencia de la enfermedad normalmente con penicilina benzatina cada 3 o 4 semanas. En cuanto al pronóstico es generalmente bueno tras el episodio inicial de FR y todos los síntomas suelen solucionarse completamente con excepción del daño de la válvula cardíaca, que puede progresar con el tiempo, especialmente con episodios subsecuentes de fiebre 


\section{Daño cardíaco por fiebre reumática activa}

Vol. 3, núm. 4., (2019)

Freddy Leónidas Monge Paladines; Victoria Magdalena Paladines Ríos

reumática, y requerir manejo médico crónico para el fallo cardíaco y eventualmente cirugía de recambio valvular.

La fiebre reumática puede ser prevenida con la profilaxis y el tratamiento de las infecciones estreptocócicas agudas. Las infecciones estreptocócicas agudas son tratadas con una inyección única de 0.6-1.2 millones de unidades de penicilina benzatina, aunque esta inyección es muy dolorosa. Otra alternativa es la utilización de penicilina V durante 10 días. Todos los pacientes que han tenido fiebre reumática aguda deben de recibir tratamiento profiláctico durante meses o incluso años. Se administra penicilina benzatina inyectada mensualmente, 0.6 a 1.2 millones de unidades, o bien se pueden recibir $125 \mathrm{mg}$ de penicilina $\mathrm{V}$ oral 2 veces al día. Se recomienda mantener esto hasta que se cumplan los 25 años.

\section{Conclusiones.}

El desarrollo del contenido teórico lleva al investigador a generar argumentaciones propias como resultado de aquellas interpretaciones logradas durante el desarrollo de los eventos que han sido insertados a todo lo lardo del presente artículo, entre ellas se citan las siguientes:

Al hacer referencia a la enfermedad reumática cardíaca, se puede indicar que la misma provoca un daño en las válvulas cardíacas; pues, es una enfermedad inflamatoria que se produce como complicación de la faringitis estreptocócica o escarlatina tratada inadecuadamente. Es más frecuente entre los 5 y 15 años y afecta más a mujeres. Por ello, amerita un diagnóstico seguro que determine de forma precisa los síntomas y signos, dado que, las infecciones de la faringe no necesariamente estiman la presencia de la fiebre reumática, de allí, que la exploración mediante 


\section{Daño cardíaco por fiebre reumática activa}

Vol. 3, núm. 4., (2019)

Freddy Leónidas Monge Paladines; Victoria Magdalena Paladines Ríos

exámenes de laboratorios para estimar la presencia de estreptococos tipo $\mathrm{A}$, le asegure al médico la asignación del tratamiento correcto.

Cabe agregar que en los países desarrollados, como resultado a las múltiples investigaciones y presencia de laboratorios especializados en serología de estreptococos han disminuido considerablemente su prevalencia. Pero en las naciones en vía de desarrollo continua siendo una necesidad de salud general. De igual manera, es importante resaltar que el curso de la fiebre reumática es variable e impredecible. En algunos pacientes que están aparentemente graves, la recuperación completa ocurre en pocos días, mientras que en otros la enfermedad persiste durante meses.

El primer ataque es normalmente fatal, con probable afectación del corazón, aunque las recurrencias pueden desencadenar más daño cardiaco, incluso insuficiencia biventricular. Más de dos tercios de los pacientes que han tenido fiebre reumática, suelen tener enfermedad reumática valvular crónica. No hay duda de que muchos casos de fiebre reumática se escapan al diagnóstico, porque alrededor de la mitad de los pacientes con enfermedad reumática crónica, no refieren historia de episodio agudo.

La enfermedad cardiaca crónica reumática es el resultado del daño producido por ataques recurrentes de carditis reumática aguda y el consiguiente proceso de cicatrización que acontece tras la fase inflamatoria inicial. Estos cambios están confinados a las estructuras valvulares, aunque a veces el daño miocárdico puede ser también severo. Es importante reconocer que el daño miocárdico puede coexistir, y que la corrección de una anormalidad valvular no necesariamente restablece la función cardiaca normal. El proceso patológico que ocurre en las 


\section{Daño cardíaco por fiebre reumática activa}

Vol. 3, núm. 4., (2019)

Freddy Leónidas Monge Paladines; Victoria Magdalena Paladines Ríos

válvulas incluye el engrosamiento y la distorsión de las valvas, fusión de las comisuras y acortamiento de las cuerdas tendinosas. Las deformidades valvulares tardan tiempo en desarrollarse, y el estrechamiento no es grave hasta que el orificio se reduce hasta la cuarta parte de su diámetro. La insuficiencia valvular puede ser importante desde el momento del ataque de la fiebre reumática aguda, pero hasta hacerse sintomática, puede pasar tiempo.

\section{Bibliografía.}

Duarte, M. (2018). Trabajos y Monografías Científicas. Buenos Aires: Planeta.

Neira, O. (2018). Infecciones en Reumatología. Salud, 7-24.

Ramos, V. (2019). Ciencia como Medio de Investigación. México: Gedisa.

Rodríguez, A. y. (58-69). Fiebre Reumática. Salud.

Torres, J. (2017). La Cardiopatía Reumática en la Actualidad. Infac, 7-24.

Villa, Mandell, A. y., \& B. (2016). Trastornos Cardiovasculares y Enfermedad Reumática. Española de Cardiología, 809-817.

$$
\text { (9) (1)( })
$$

RECONOCIMIENTO-NOCOMERCIAL-COMPARTIRIGUAL

CC BY-NC-SA

ESTA LICENCIA PERMITE A OTROS ENTREMEZCLAR, AJUSTAR Y CONSTRUIR A PARTIR DE SU OBRA CON FINES NO COMERCIALES, SIEMPRE Y CUANDO LE RECONOZCAN LA AUTORÍA Y SUS NUEVAS CREACIONES ESTÉN BAJO UNA LICENCIA CON LOS MISMOS TÉRMINOS. 